\title{
Somatostatin. The beginnings, 1972
}

\author{
Roger Guillemin \\ The Salk Institute, La Jolla, California
}

\begin{abstract}
The isolation and characterization of TRF (TRH) in 1968 made the hypothesis of the existence of hypothalamic releasing factors into a scientific fact, requiring de facto, the search for other releasing factors involved in controlling the secretion of all (anterior) pituitary hormones. Indeed, LRF (LHRH, GnRH) stimulating the secretion of LH and FSH was characterized in 1970. A releasing factor for growth hormone $(\mathrm{GH})$, postulated since 1960, was next, notwithstanding an early report by Schally's group, which turned out to be an unfortunate artifact. We then set up a highly sensitive and specific radioimmunoassay for rat growth hormone (Paul Brazeau, a new post-doc in the lab) and started adding crude extracts of sheep hypothalamus to anterior pituitary cells maintained in vitro with the elegant monolayer culture method recently developed by Wylie Vale. To our surprise, in repeated experiments we kept observing an inhibition of the secretion of growth hormone, linearly related to the amounts of hypothalamic extracts added ( $\geq 0.001$ of a hypothalamic fragment). The results were so consistent that we eventually eliminated the possibility (indeed first considered) of an artifact. There had been, actually, an earlier report (Krulich et al) claiming inhibition or stimulation of growth hormone release by crude extracts of different parts of the hypothalamus, but with borderline statistical significance. So, we decided to isolate and characterize whatever in these crude extracts was inhibiting the secretion of growth hormone (while at the same time, these same crude extracts could be shown to stimulate release of TSH and LH).
\end{abstract}

With our radioimmunoassay for rat growth hormone, we tested aliquots of the whole effluent still available from the isolation of LRF and rapidly identified a zone well separated from LRF with the GH-release inhibiting activity. Several steps of purification later, Roger Burgus, who was in charge of this whole isolation procedure, isolated a single compound accounting for all the GH-release inhibiting activity of the crude extract, showed it to be composed of 14 residues, sequenced it by manual Edman degradation (1 residue per day), Nicholas Ling confirming the sequence of the fragments by mass spectrometry, got a molecular structure that Jean Rivier synthesized by Merrifield method, Wylie Vale and Paul Brazeau showing the biological activity of the synthetic molecule in vitro and in vivo (in the rat). The paper was written, sent to Science on September 2, 1972, accepted on October 20, 1972, and published on January 5, 1973 (v. 179, pp 77-79). There is when I suggested the name somatostatin, preferred over the acronyms SRIF (for Somatotropin-Release-Inhibiting Factor) or GHRIF !.

As reported in the Science paper we showed with Sam Yen that our synthetic peptide was highly active in lowering plasma GH-levels in a few acromegalic patients.

As a part of my ethics in the lab, we started sending mgs of our synthetic peptide to any colleague asking for some, the only condition being would they please let us know what they observed with it in their own studies. One day, we received a couple of calls from Charlie Gale

\footnotetext{
Publisher's Disclaimer: This is a PDF file of an unedited manuscript that has been accepted for publication. As a service to our customers we are providing this early version of the manuscript. The manuscript will undergo copyediting, typesetting, and review of the resulting proof before it is published in its final citable form. Please note that during the production process errors may be discovered which could affect the content, and all legal disclaimers that apply to the journal pertain.
} 
in Seattle who said that in their studies in baboons they regularly observed the peptide to lower plasma levels of GH but also of glucagon and insulin. We never saw such effects in rats but Sam Yen confirmed the results of the Seattle group in going back to the blood samples of the original patients mentioned earlier. Knowing the plasma half-life and barely detectable levels of the polypeptide in peripheral-rat blood, it occurred to me that perhaps some local source in the pancreas might be responsible, my original idea being possibly the nerve endings of the vagus nerve, since I had just received from Peter Petrusz stunning images of somatostatinimmunoreactive neurons in parts of the brain other than the hypothalamus. The surprise came when Maurice Dubois of the INRA (Institut National de la Recherche Agronomique) in Nouzilly with some antibodies I had sent him and Rolf Luft and Tomas Hökfelt in Stockholm independently showed immunoreactive somatostatin in the delta-cells of the endocrine pancreas, delta-cells for which no activity was known to that day. Then came literally a flood of papers from the group around Reginald Hall, Mike Besser in London on the presence and effects of somatostatin in the upper GI tract, etc. Meanwhile, Jean Rivier had synthesized a large number of analogs, bioassayed by Paul Brazeau and Wylie Vale showing minimal active sequences of the original tetradecapeptide as well as some with relative specificity for the secretion of one of the original three targets.

Those were the beginnings. Then things developed with industry (octreotide, lanreotide), molecular biology, the several forms of the precursors, the multiple receptors etc. and all that is to be read in that special issue of the Journal. A wonderful feeling.

Cortistatin, which is developing remarkably well, came as a surprise in 1995, from the group around Luis de Lecea, then at The Scripps Research Institute, - next door to the Salk Institute. I met Luis de Lecea for the first time at a meeting on sleep, last February (2007)! 


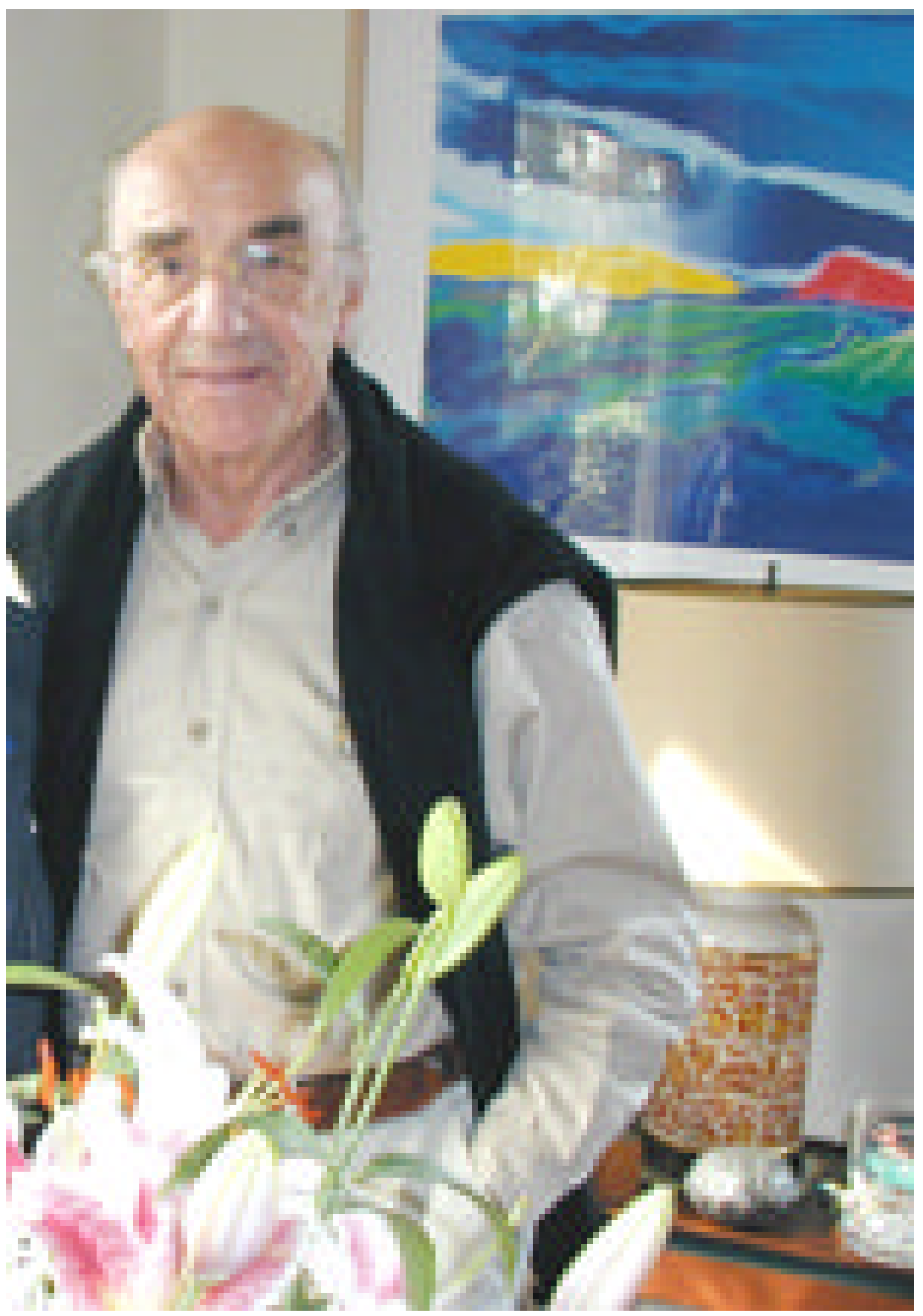

